University of Nebraska - Lincoln

DigitalCommons@University of Nebraska - Lincoln

Michigan Bovine Tuberculosis Bibliography and

Database

Wildlife Disease and Zoonotics

2002

\title{
Bovine Tuberculosis in Michigan Wildlife and Livestock
}

Stephen M. Schmitt

Wildlife Disease Laborato y, Rose Lake Wildlife Research Station, Michigan Department of Natural

Resources, East Lansing, Michigan 48823, USA

Daniel J. O'brien

Wildlife Disease Laborato y, Rose Lake Wildlife Research Station, Michigan Department of Natural

Resources, East Lansing, Michigan 48823, USA

Colleen S. Brunning-Fann

eterina Services, Animal and Plant Health Inspection Service, United States Department of Agriculture, East Lansing, Michigan 48823, USA

Scott D. Fitzgerald

Animal Health Diagnostic Laboratory and Department of Pathology, College of Veterina y Medicine, Michigan State University, East Lansing, Michigan 48824, USA

Follow this and additional works at: https://digitalcommons.unl.edu/michbovinetb

Part of the Veterinary Medicine Commons

Schmitt, Stephen M.; O'brien, Daniel J.; Brunning-Fann, Colleen S.; and Fitzgerald, Scott D., "Bovine Tuberculosis in Michigan Wildlife and Livestock" (2002). Michigan Bovine Tuberculosis Bibliography and Database. 114.

https://digitalcommons.unl.edu/michbovinetb/114

This Article is brought to you for free and open access by the Wildlife Disease and Zoonotics at DigitalCommons@University of Nebraska - Lincoln. It has been accepted for inclusion in Michigan Bovine Tuberculosis Bibliography and Database by an authorized administrator of DigitalCommons@University of Nebraska Lincoln. 


\title{
Bovine Tuberculosis in Michigan Wildlife and Livestock
}

\author{
STEPHEN M. SCHMITT, ${ }^{a}$ DANIEL J. O'BRIEN, ${ }^{a}$ COLLEEN S. BRUNING-FANN,${ }^{b}$ \\ AND SCOTT D. FITZGERALD ${ }^{c}$ \\ ${ }^{a}$ Wildlife Disease Laboratory, Rose Lake Wildlife Research Station, Michigan \\ Department of Natural Resources, East Lansing, Michigan 48823, USA \\ ${ }^{b}$ Veterinary Services, Animal and Plant Health Inspection Service, United States \\ Department of Agriculture, East Lansing, Michigan 48823, USA \\ ${ }^{c}$ Animal Health Diagnostic Laboratory and Department of Pathology, College of \\ Veterinary Medicine, Michigan State University, East Lansing, Michigan 48824, USA
}

\begin{abstract}
Since 1994, the state of Michigan has recognized a problem with bovine tuberculosis (TB), caused by Mycobacterium bovis, in wild white-tailed deer from a 12-county area in northeastern Lower Michigan. A total of 65,000 freeranging deer have been tested, and 340 have been found to be positive for $M$. bovis. The disease has been found in other wildlife species, and, in 1998, in domestic cattle, where to date 13 beef cattle and 2 dairy cattle herds have been diagnosed with bovine TB. Unfortunately, the situation is unique in that there have never been reports of self-sustaining bovine TB in a wild, free-ranging cervid population in North America. Scientists, biologists, epidemiologists, and veterinarians who have studied this situation have concluded that the most logical theory is that high deer densities and the focal concentration caused by baiting (the practice of hunting deer over feed) and feeding are the factors most likely responsible for the establishment of self-sustaining TB in free-ranging Michigan deer. Baiting and feeding have been banned since 1998 in counties where the disease has been found. In addition, the deer herd has been reduced by $50 \%$ in the endemic area with the use of unlimited antlerless permits. The measures of apparent TB prevalence have been decreased by half since 1997, providing hopeful preliminary evidence that eradication strategies are succeeding.
\end{abstract}

KEYWORDS: bovine tuberculosis; Mycobacterium bovis; white-tailed deer

Since 1994, the state of Michigan has recognized a problem with bovine tuberculosis, caused by Mycobacterium bovis, in wild white-tailed deer (Odocoileus virginianus) from a 12-county area in northeastern Lower Michigan (FIG. 1). A total of 64,423 free-ranging deer have been tested, and 340 have been found to be positive for $M$. bovis (TABLE 1). The disease has been found in other wildlife species, including 1 elk (Cervus elaphus), 13 coyotes (Canus latrans), 2 raccoons (Procyon lotor), 2 opossums (Didelphis virginiana), 2 bobcats (Felis rufus), 4 black bear (Ursus americanus), and 2 red fox (Vulpes vulpes) (TABLE 2), and, in 1998, in domestic cat-

Address for correspondence. Dr. Stephen M. Schmitt, Wildlife Disease Laboratory, Rose Lake Wildlife Research Station, Michigan Department of Natural Resources, East Lansing, MI 48823. Voice: 517-373-9358; fax: 517-641-6022.

schmitts@state.mi.us

Ann. N.Y. Acad. Sci. 969: 262-268 (2002). (C) 2002 New York Academy of Sciences. 


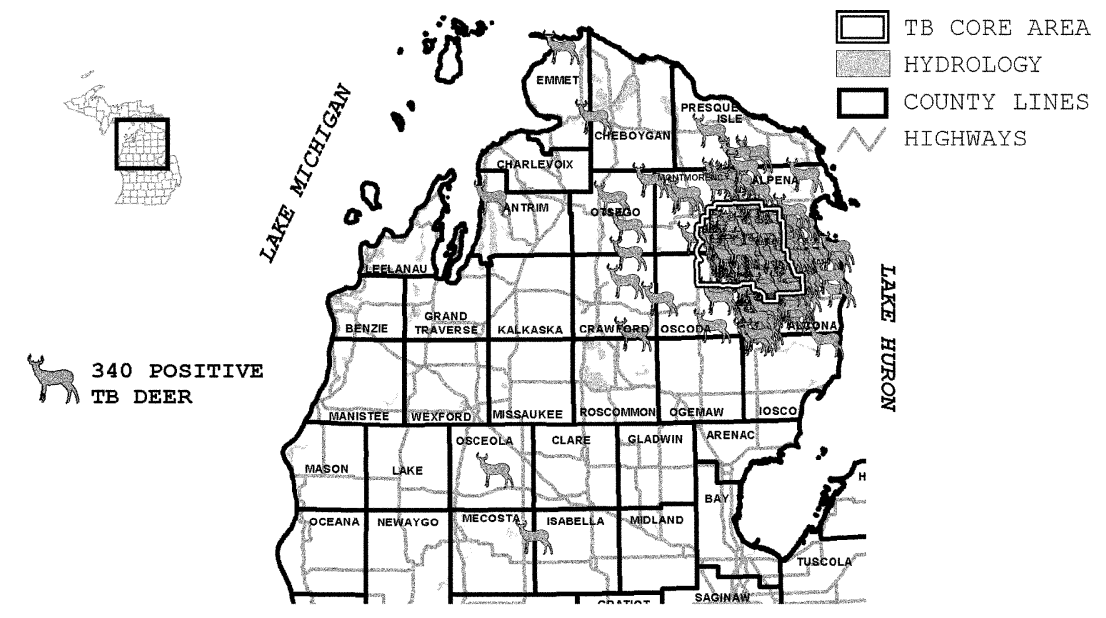

FIGURE 1. Location of Mycobacterium bovis-infected white-tailed deer in Michigan, 1975, 1994-2001.

tle, where to date 14 beef and 2 dairy cattle herds have been diagnosed with bovine tuberculosis.

Recognizing the potential economic and public health consequences of bovine tuberculosis to the state, the governor has issued orders to eradicate M. bovis from the state's deer population. Unfortunately, the situation is unique in that there have never been reports of self-sustaining bovine TB in a wild, free-ranging cervid population in North America. There are no existing control programs for bovine TB in wild deer, and there is much about bovine TB in deer that is currently unknown. Scientists, biologists, epidemiologists, and veterinarians who have studied this situation have concluded that the most logical theory is that high deer population densities and the focal concentration caused by baiting (the practice of hunting deer over feed) and feeding are the factors most likely responsible for the establishment of self-sustaining bovine TB in free-ranging Michigan deer. ${ }^{1}$ By congregating deer into close contact with each other repeatedly, baiting and feeding provide ideal conditions for the transmission of bovine TB via both inhalation of infectious aerosols and ingestion of bovine TB-contaminated feed. ${ }^{2}$

The elimination of bovine TB from free-ranging deer is likely to be a difficult goal, but it is an extremely important one to accomplish. It will require the cooperation and collaboration of state and federal animal health and wildlife resource agencies. Animal health agencies do not have sufficient expertise in wildlife biology and management techniques to address the situation independently; the same can be said for wildlife resource agencies faced with diseases in domestic animal populations. Therefore, multiple agencies must rely on each other and work collaboratively to deal with the control of disease in wildlife; unilateral efforts cannot be expected to succeed. It should be understood that wildlife resource agencies want their freeranging wildlife populations to be free of disease just as much as animal health agencies want domestic animals to be free of disease. ${ }^{3}$ 
TABLE 1. Summary of bovine tuberculosis testing of free-ranging white-tailed deer in Michigan by year

\begin{tabular}{ccc}
\hline Year & Tested positive & Total tested \\
\hline 1975 & 1 & 1 \\
1994 & 1 & 1 \\
1995 & 27 & 814 \\
1996 & 47 & 4471 \\
1997 & 73 & 3705 \\
1998 & 78 & 9067 \\
1999 & 58 & 19,500 \\
2000 & 53 & 25,857 \\
2001 (ongoing) & 2 & 1007 \\
Total & 370 & 64,423 \\
\hline
\end{tabular}

TABLE 2. Summary of noncervid wildlife tuberculosis testing by species

\begin{tabular}{lrr}
\hline \multicolumn{1}{c}{ Species } & Tested & Positive \\
\hline American badger (Taxidea taxus) & 25 & \\
Black bear (Ursa americanus) & 153 & 4 \\
Bobcat (Felis rufus) & 53 & 13 \\
Coyote (Canus latrans) & 291 & \\
Feral cat (Felis domesticus) & 25 & \\
Feral dog (Canis domesticus) & 1 & \\
Gray fox (Urocyon cinereoargenteus) & 4 & \\
Mink (Mustela vison) & 3 & \\
Opossum (Didelphis virginiana) & 261 & \\
Northern river otter (Lutra canadensis) & 8 & 2 \\
Porcupine (Erithizon dorsatum) & 1 & \\
Raccoon (Procyon lotor) & 220 & \\
Red fox (Vulpes vulpes) & 18 & \\
Striped skunk (Mephitis mephitis) & 21 & \\
Snowshoe hare (Lepis americanus) & 1 & \\
Long-tailed weasel (Mustela frenata) & 1 & \\
$\quad$ Total & 1086 & \\
\hline
\end{tabular}

A management strategy recommended by a multiagency committee composed of individuals with disease expertise and jurisdiction included surveying wildlife populations, testing livestock, educating the public about bovine $\mathrm{TB}$, eliminating feeding and baiting of deer, reducing the deer density through legal hunting in areas of 
Michigan where bovine TB has been found, and banning the transport of free-ranging deer from the infected area.

A comprehensive statewide program of surveillance of free-ranging deer populations is necessary to identify areas that will need intensified management practices, and to monitor the success of these practices. The continued evaluation of the prevalence of the disease allows the Michigan Department of Natural Resources to determine the reservoir of existing disease, define geographic areas of infection, and assess trends in disease occurrence. Such information will need to be collected for many years in order to interpret trends. The deer surveillance plan focuses on areas that are most likely to have bovine TB-positive free-ranging deer. The plan is science based, using past and present livestock infection rates, locations of livestock, areas of deer density, and appropriate sample sizes for statistical analysis. The plan is coordinated with surveillance of livestock conducted by the Michigan Department of Agriculture, and it is practical in terms of manpower, money, and laboratory capacities.

A strong education program is necessary to bring about public understanding of, develop support for, and encourage participation in the TB eradication project. Improved communication, both at the grassroots level and through statewide marketing, is vital to the success of the education program. Continued and enhanced contact with key audiences (i.e., livestock producers, industry representatives, the media, hunters, and recreational wildlife viewers) will lead to an understanding of the recommended strategies for $M$. bovis eradication in the white-tailed deer and livestock populations. Examples of ongoing education efforts include Michigan Department of Natural Resources/Michigan Department of Agriculture/Michigan State University extension training sessions, bovine TB brochures and newsletters, the annual Bovine TB in Michigan conference, a bovine TB web site, infomercials, satellite training sessions, and press packets.

Methods employed for eradicating bovine TB from free-ranging Michigan deer should decrease the transmission of bovine TB among deer. Reduction of transmission can be enhanced in two ways: reduction in the number of infected animals, and reduction in the amount of contact (direct or indirect) between infected and susceptible animals. Increasing the hunter harvest of deer will reduce the overall number of deer as well as reduce the average age of the deer population. Hunting regulations should be liberalized to remove greater numbers of antlerless deer to control deer populations and to remove greater numbers of adult males because a higher prevalence of bovine TB has been observed in adult male deer in Michigan (TABLE 3 ). The goal of liberalized hunting regulations should be a smaller deer herd with a younger age structure.

Elimination of baiting and supplemental feeding of deer will reduce the deer population as the herd density approaches the carrying capacity of the land, and will decrease contact among deer. Artificial feed supplies (baiting and supplemental feeding) increase the density of deer populations beyond the carrying capacity. Even if the deer herd density is not artificially inflated, the presence of feed and bait encourages unnatural congregation of the animals, thereby increasing contact among deer and enhancing the transmission of infectious agents. Large numbers of animals in close proximity for extended periods of time are more likely to inhale infected aerosolized droplets or to consume food contaminated by coughing and exhalation. ${ }^{1}$ 
TABLE 3. Bovine tuberculosis apparent prevalence for endemic area by year and various sex and age groupings

\begin{tabular}{cccccc}
\hline & \multicolumn{2}{c}{ Both sexes } & & \multicolumn{2}{c}{ Two years and older } \\
\cline { 2 - 3 } \cline { 5 - 6 } Year & All ages & Yearlings & & Does & Bucks \\
\hline 1996 & $2.3 \%$ & $1.3 \%$ & & $2.7 \%$ & $4.0 \%$ \\
1997 & $4.4 \%$ & $1.5 \%$ & & $4.7 \%$ & $9.5 \%$ \\
$1998^{a}$ & $2.4 \%$ & $1.4 \%$ & & $1.9 \%$ & $7.7 \%$ \\
$1999^{b}$ & $2.2 \%$ & $0.6 \%$ & & $2.8 \%$ & $4.3 \%$ \\
$2000^{c}$ & $2.3 \%$ & $0.6 \%$ & & $2.1 \%$ & $4.9 \%$ \\
\hline
\end{tabular}

${ }^{a}$ Feeding banned, baiting restricted, doe harvest increased.

${ }^{b}$ Continued feeding ban, baiting banned, doe harvest increased.

${ }^{c}$ Continued feeding ban, baiting banned.

The discovery of endemic tuberculosis in deer coupled with the wide host range of Mycobacterium bovis ${ }^{4}$ the causative agent of bovine TB, provided the impetus for a survey of other wild species present in the area. ${ }^{5}$ Wildlife species selected for inclusion in the ongoing study are those noncervid mammalian species present in the area where deer have been found with bovine TB and whose population density was sufficient to allow collection. Species that have been tested in this survey are the badger (Taxidea taxus), black bear, bobcat, coyote, feral cat (Felis domesticus), feral dog (Canis domesticus), gray fox (Urocyon cinereoargonteus), mink (Mustela vison), opossum, otter (Lutra canadensis), porcupine (Erithizon dorsatum), raccoon, red fox, striped skunk (Mephitis mephitis), snowshoe hare (Lepus americanus), and long-tailed weasel (Mustela frenata). To date, 1080 noncervid animals have been tested, with 13 coyotes, 2 raccoons, 4 black bear, 4 bobcats, 2 red fox, and 2 opossums found or suspected to be infected with Mycobacterium bovis (FIG. 2). Since all six of these species are known to be opportunistic scavengers, ${ }^{6}$ the most likely source of infection for these animals was through the consumption of tuberculous white-tailed deer. ${ }^{7}$

Cranial, thoracic, and abdominal lymph nodes, as well as any gross lesions, are collected routinely for histology and mycobacterial culture from all noncervid carcasses examined. ${ }^{7}$ Designation as infected is based solely on positive culture results. The lack of any gross or microscopic lesions in the vast majority of Michigan noncervids tested thus far indicates that these animals were either infected recently (sufficient time had not elapsed to allow the development of lesions) or that the development of discernable lesions was impaired due to the relative resistance of these animals to tuberculosis. ${ }^{4}$ Thus far, high numbers of bacteria have not been associated with lesions from the native Michigan noncervid wildlife. Without extensive lesion development containing enormous numbers of bacteria and an avenue of excretion of the bacteria from the body, successful disease transmission to other animals is doubtful.

The number of tuberculous noncervid wildlife, the variety of species involved, and the geographic spacing between the cases is more indicative of disease spillover from free-ranging deer, the primary reservoir to these noncervid wildlife species, rather than of endemic tuberculosis. Although it is currently thought that no wildlife 


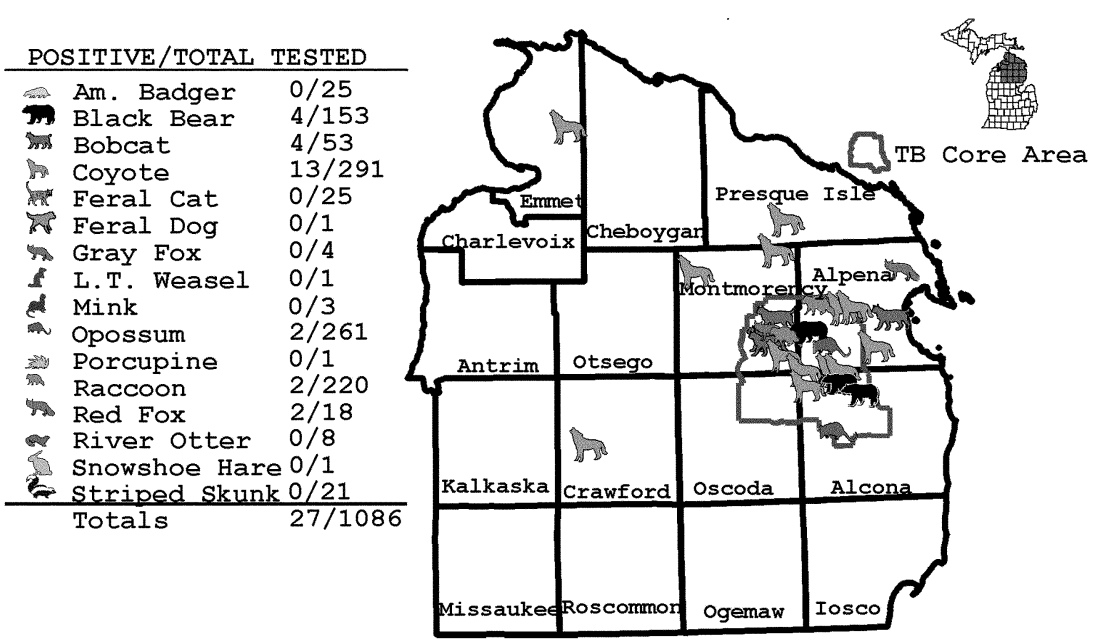

FIGURE 2. Location of Mycobacterium bovis-infected noncervid wildlife in Michigan, 1996-2001.

other than white-tailed deer serve as a reservoir for tuberculosis in Michigan, continued and expanded wildlife surveys and experimental inoculation studies are in progress.

Michigan has a small elk population of approximately 1200 animals, whose range overlaps into the area of Michigan where TB-positive deer have been found. Since 1984, tightly controlled annual elk hunts have been held in Michigan, and almost 3500 elk have been harvested. All of the elk carcasses and gut piles were examined; no TB lesions were noted. With the discovery of bovine tuberculosis in the whitetailed deer population that shares much of the elk range, hunters were asked in 1996 to voluntarily turn in elk heads to be examined for bovine TB. Since 1998, hunterharvested elk head submission has been mandatory. Along with road kills and other losses, a total of 848 elk have been tested for the disease from May 1996 to present. To date, 1 adult female elk has been confirmed positive for bovine TB, having exhibited a unilateral tonsil lesion. Analysis by restriction fragment length polymorphisms of DNA extracted from the TB isolate cultured from this elk indicates that it is the same strain found in infected cattle, deer, and other wildlife in the area. It is believed that the elk herd has recently, in the last several years, been infected with bovine TB.

In summary, the two main strategies for eradicating bovine $\mathrm{TB}$ from free-ranging Michigan deer are to minimize concentrations of deer by eliminating baiting and feeding and to reduce deer numbers through hunting to the biological carrying capacity. Baiting and feeding have been banned since 1998 in counties where the disease has been found. In addition, the deer herd has been reduced by $50 \%$ in the endemic area with the use of unlimited antlerless permits. The measures of apparent bovine TB prevalence have decreased by half since 1997, providing hopeful preliminary evidence that eradication strategies are succeeding. 


\section{REFERENCES}

1. Schmitt, S.M., S.D. Fitzgerald, T.M. Cooley, et al. 1997. Bovine tuberculosis in free-ranging white-tailed deer from Michigan. J. Wildl. Dis. 33(4): 749-758.

2. Whipple, D.L. \& M.V. Palmer. 2000. Survival of Mycobacterium bovis on feeds used for baiting white-tailed deer (Odocoileus virginianus) in Michigan. In 49th Annual Wildlife Disease Association Conference Proceedings: 21. Wildlife Disease Association, Grand Teton National Park, Wyoming.

3. Salman, M.D., M. Miller, J. Clifford, et al. 2000. Report of the USAHA working group on tuberculosis: domestic animal/wildlife interface. In Proceedings: One Hundred and Fourth Annual Meeting of the United States Animal Health Association, Birmington, Alabama. Carter-Printing Company. Richmond, VA, pp. 659-660.

4. Francis, J. 1958. Tuberculosis in Animals and Man. Cassell. London.

5. Bruning-FAnN, C.S., S.M. Schmitt, S.D. FitzGerald, et al. 1998. Mycobacterium bovis in coyotes in Michigan. J. Wildl. Dis. 34: 632-636.

6. BaKer, R.H. 1983. Michigan Mammals. Michigan State University Press. East Lansing, MI.

7. Bruning-Fann, C.S., S.M. Schmitt, S.D. FitzGERAld, et al. 2001. Bovine tuberculosis in free-ranging carnivores from Michigan. J. Wildl. Dis. 37: 58-64. 